\title{
Reliability-based Approach to Optimal Economic Estimation of Concrete Cover Thickness under Carbonation Environment
}

\author{
Jeong-Yun Do, ${ }^{1)}$ Dookie Kim, ${ }^{2)}$ Hun Song, ${ }^{3)}$ and Young-Kug Jo ${ }^{4)}$
}

(Received June 4, 2009, Revised November 13, 2009, Accepted November 13, 2009)

\begin{abstract}
Concrete carbonation is a cause of problems in concrete structures, so it needs to be estimated. And concrete cover is designed to protect structures from this damaging. Usually the cover thickness is considered based on the limit states design codes in which the important target is the reliability safety index. However, it is not clear that whether the safety index determined is optimal or not with respect to the cost. The codes are mainly proceeded quantitatively (i.e. making a safe structure) while the economic aspects are only considered qualitatively. So the reliability-based design considering life cycle cost (LCC) is called for, and here the focus is on the advanced analysis solution to optimize the reliability safety regarding LCC.
\end{abstract}

Keywords: concrete carbonation, concrete cover thickness, limit state reliability safety index, optimal LCC

\section{Introduction}

Structures are usually designed to live up for the designed lifetime at least. During its lifetime, it should withstand many external factors, including carbonation corroding. Carbonation of concrete structures has been a concern more and more nowadays as the global warming goes on, especially in the urban environment.

It is well known that reinforcement corrosion is affected by the concrete cover thickness, and therefore general concrete structures are required to have a minimum cover thickness to maintain a strong bond between the steel and concrete to prevent corrosion, or in other words, to guarantee the structure's safety and serviceability.

Based on the reliability theory, the probability of failure depends on the ratio of the mean value of the limit state function to its standard deviation. This ratio is commonly known as the safety index or reliability index. The safety index is selected in levels to meet the different safety and serviceability demands of the structure. However, it is not clear whether or not the safety index selected through the code calibration is optimal with respect to the cost, because in the calibration the structural safety is achieved quantitatively in an analytical manner, while the economic aspects are only considered qualitatively. There exists an optimal safety

\footnotetext{
${ }^{1)}$ KCI Member, BK21 Research Team, Kunsan National University, Kunsan 573-701, Korea. Email: arkido@hotmail.com.

${ }^{2)}$ KCI Member, Civil and Environmental Engineering, Kunsan National University, Kunsan 573-701, Korea.

${ }^{3)}$ KCI Member, Dept. of Green Ceramic, Korea Institute of Ceramic Engineering \& Technology, Seoul 153-801, Korea.

${ }^{4)}$ KCI Member, Dept. of Architectural Engineering, Chungwoon University, Chungnam 350-701, Korea.

Copyright (c) 2009, Korea Concrete Institute. All rights reserved, including the making of copies without the written permission of the copyright proprietors.
}

level which leads to the minimum total cost of the building. A survey suggests that the selected target safety level in current design codes are on the right hand side of the optimal safety level. Various attempts have been made to achieve a proper safety. ${ }^{1,2}$ In this study, the optimization concept is performed in choosing the most economical safety index, i.e. getting the optimal balance between the total cost (mainly includes initial cost, maintenance cost and the cost for building failure of its function) and the safety index as shown in Fig. 1.

\section{Theoretical background}

\subsection{Effect of $\mathrm{CO}_{2}$ on concrete structures}

The carbonation of concrete is a natural phenomenon that is progressed with elapsed time and causes reinforcement corrosion in the concrete. The global warming phenomenon due to the increase in temperature and $\mathrm{CO}_{2}$ concentration has been regarded as one of the most critical environmental problems in the $21^{\text {st }}$ century.

During the past few decades, a number of studies on carbonation prediction has been carried out and studies on carbonation have proved a square-root $(\sqrt{t})$ law in approximating the results obtained from a colorimetric method using phenolphthalein., The rate of carbonation is usually assumed to be

$$
\mathrm{X}_{\mathrm{C}}=\mathrm{K}_{\mathrm{C}} \sqrt{t}
$$

where $X_{C}$ is the depth of carbonation at time $t$, and $K_{C}$ is the carbonation coefficient. The relationship between $X_{C}$ and $t$ is shown in Fig. 2.

\section{Reliability concept}

Conceptually, reliability-based economic design is used to 


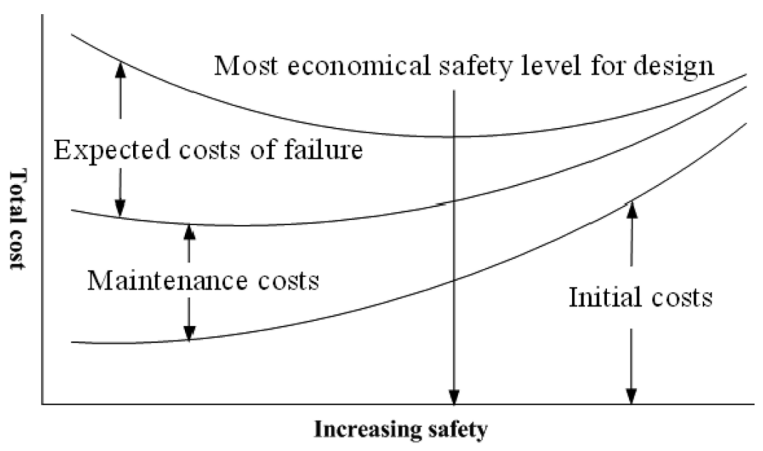

Fig. 1 Selection of reliability index to minimize total cost.

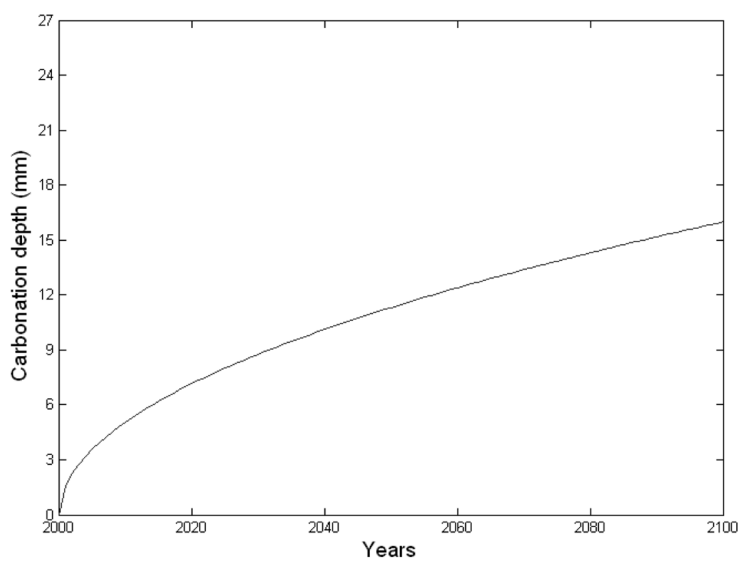

Fig. 2 Carbonation depth of concrete for the lifetime. ${ }^{6}$

determine an optimal safety level with respect to the total cost of buildings to be designed. The safety level can be quantitatively represented by the complement of the probability of building failure (collapse), which can be computed by ${ }^{5}$

$$
P_{f}=P[Z(X) \leq 0]=\int_{Z \leq 0} \int_{x}(x) d_{x}
$$

where $Z(X)$ is the limit state function for the building (structure), and $f_{x}(x)$ is the joint probability density function of the basic random variable $X$.

Using the First Order Second Moment (FOSM) method, the failure probability can be evaluated by

$$
P_{f}=\Phi(-\beta)
$$

where $\beta$ is known as the reliability index and $\Phi$ is the standard normal distribution function (Fig. 3).

$$
\Phi(-\beta)=\int_{-\infty}^{-\beta} \phi(x) d x
$$

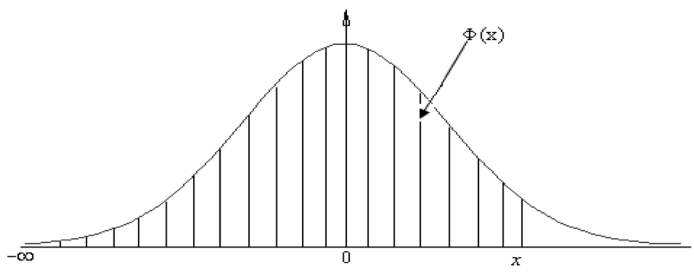

Fig. 3 Probability of failure for the standard normal distribution.

$$
\phi(x)=\frac{1}{\sqrt{2 \pi}} e^{\left(-\frac{1}{2} x^{2}\right)}
$$

\section{LCC model}

It is commonly accepted that increasing the durability of concrete will: 1) induce an increment in the cost of structure; 2) induce a decrement in the failure probability and therefore lower the damage cost.

An analysis of the life cycle costing of buildings should be included. If, for simplicity, other costs that are not directly related to structural safety such as costs due to different architecture designs, construction methods, etc. are ignored, the total cost of a building (structure) can be expressed as

$$
C_{T}=C_{I}+C_{M}+P_{f} \cdot C_{f}
$$

where $C_{T}$ is total cost of the building structure, $C_{I}$ is the initial construction cost, $C_{M}$ is the maintenance cost, and $C_{f}$ is the cost related to building collapse (failure), including human casualties.

\section{LCC-based optimal approach in this study}

\subsection{Carbonation model used in this study}

Normally, a number of approaches can be considered for the solution of service life prediction of concrete such as semi-determinant method, experimental methods related with accelerated tests based on a deterioration mechanism, mathematical modeling as an expression of degradation process of the chemistry and physics of concrete, and applicative methods of reliability or stochastic concepts. ${ }^{6,7}$ In this study, a reliable carbonation model is needed.

$$
X_{C}=1.72 \cdot R \cdot(w / c-0.38) \cdot \sqrt{t} \cdot \delta \cdot \gamma
$$

where, $R$ is the carbonation rate coefficient considering the material used (Table 1). $t$ is the structure's lifetime $\delta$ is the direction coefficient considering environmental effects (environment difficult to dry, north direction, $\delta=1.0$; environment easy to dry, south direction, $\delta=1.6), \gamma$ is the quality coefficient considering concrete quality (general, $\gamma=1.0$; upper surface, $\gamma=1.3$; in cases where the concrete of the constructed structure is not differ-

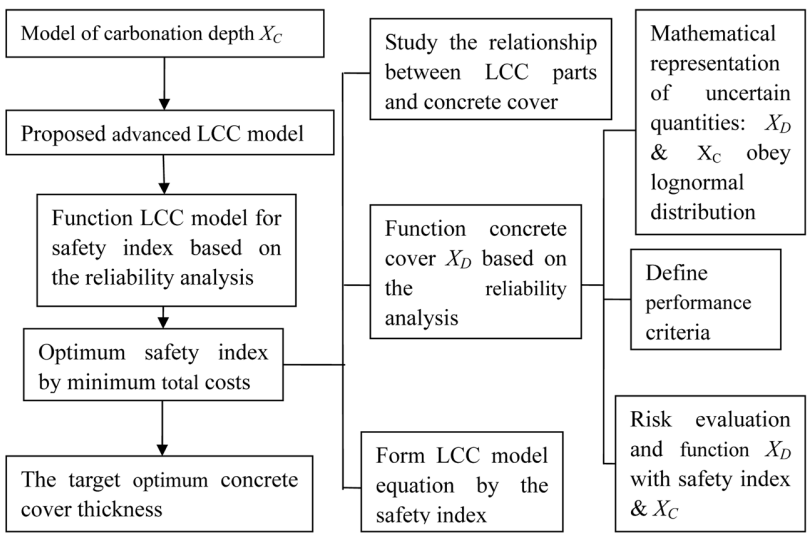

Fig. 4 Steps in the analysis process. 
Table 1 Carbonation rate coefficient depending on the type of cement and aggregate.

\begin{tabular}{|c|c|c|c|}
\hline Classification & Natural aggregate & River sand and aggregate & Crushed aggregate \\
\hline Ordinary cement & 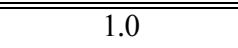 & 1.2 & 2.9 \\
\hline Early-strength cement & 0.6 & 0.7 & 1.8 \\
\hline Portland blast furnace cement (slag 30 40\%) & 1.4 & 1.7 & 4.1 \\
\hline Portland blast furnace cement (slag around 60\%) & 1.7 & 2.0 & 4.9 \\
\hline Fly-ash cement (Fly-ash 20\%) & 1.9 & 2.3 & 5.5 \\
\hline
\end{tabular}

ent with the standard curing specimens for controlling the quality of the structure, $\gamma=1.0$ ).

In this study, it is supposed that the concrete is manufactured using ordinary cement, with no agent and crushed aggregates.

\section{Proposed LCC model based on reliability analysis}

\subsection{Classical simplification for the LCC model}

As expressed previously, total costs considering the whole lifetime are composed of three parts: initial cost, maintenance cost and failure cost. In some classical LCC model study, it is accepted that maintenance costs usually do not depend on the optimization process, although this is far from being true because a good design will generally translate to low maintenance. Thus, the maintenance term can be deleted, and the total cost is rewritten as ${ }^{8,9}$

$$
C_{f}=C_{i}+\sum_{i=0}^{t} P_{f}\left(t_{i}, t_{i+1}\right) C_{f i}
$$

To obtain the initial costs $C_{I}$ in functions of durability, the classical procedure is to express the costs in a linear relationship with the reliability index, ${ }^{10}$ where $a$ is the marginal cost with respect to the safety, as

$$
C_{I}=C_{0}+a \beta
$$

And a polynomial expression has been obtained in order to relate the reliability index in terms of the failure probability ${ }^{8,9}$

$$
\begin{aligned}
& \Phi(-\beta) \approx a_{0}+a_{1} \beta+a_{2} \beta^{2}+a_{3} \beta^{3} \\
& \mathrm{a}_{0}=0.5 ; \mathrm{a}_{1}=-0.4674757 ; \mathrm{a}_{2}=0.1288751 ; \mathrm{a}_{3}=-0.0085452 ;
\end{aligned}
$$

Then, the total costs are formed as a function of the safety index, and the theoretical optimum safety index can be obtained.

Obviously, in the process of evaluating the equation above and that of $C_{I}$, there will be an error because the value of $a$ should be more definite.

Thus, the limitations will be improved in this study by directly formulating the limit state function into the equation of the reliability index $\beta$, without approximation such as polynominal fitting.

\section{Improved LCC model based on reliability analysis}

\subsection{LCC model used in this study}

Based on the total costs, there should be three parts. However, in the absence of reliable data, instead of ignoring the maintenance part it may be reasonable to assume that the maintenance cost is a fraction of the initial cost of a building. During the study, the maintenance effect can be evaluated by a factor so that the total cost becomes

$$
C_{T}=(1+\lambda) \cdot C_{I}+P_{f} \cdot C_{f}
$$

here, $\lambda$ is a factor that depends on the effort of maintenance. It may be understandable that the exact value of $\lambda$ can only be determined on a case to case basis, but the value of $\lambda$ does not affect the derivation of the optimal reliability index so that any reasonable value can be used according to a certain case. ${ }^{11}$

The initial cost is shown as

$$
C_{I}=W_{d} \cdot\left[A_{s} \cdot \operatorname{Costs}+\left(h+\frac{d}{2}+X_{D}\right) \cdot \operatorname{Costc}\right]
$$

where, $A_{s}$ is the required reinforcement area per unit length, $h$ is the effective depth of the concrete slab, $d$ is the diameter of the steel, $W_{d}$ is the width of the slab, and Costs and Costc are the cost per unit volume of the steel and concrete, respectively.

For simplification, it can be rewritten as

$$
C_{I}=C_{0}+X_{D} \cdot W_{d} \cdot \text { Costc }
$$

In which

$$
C_{0}=W_{d} \cdot A_{s} \cdot \operatorname{Costs}+\left(h+\frac{d}{2}\right) \cdot \operatorname{Costc}
$$

Equation (3) shows the linear relationship between $C_{I}$ and $X_{D}$.

Estimating the $\operatorname{cost} C_{f}$ is difficult. Therefore, $C_{f}$ is assumed to be related to the construction cost and is calculated in this section by assuming a cost factor

$$
C_{f}=A \cdot W_{d} \cdot \text { Costc }
$$

The cost factor has two values: 30 and $50 .^{13}$

Then, the total costs can be expressed as:

$$
\begin{aligned}
C_{T}= & (1+\lambda) \cdot C_{0}+(1+\lambda) \cdot W_{d} \cdot \operatorname{Costc} \cdot X_{D} \\
& +P_{f} \cdot A \cdot W_{d} \cdot \operatorname{Costc}
\end{aligned}
$$

In this equation, $P_{f}$ and $X_{D}$ are the variables while the others are either constants or factors.

\subsection{Reliability analysis for costs to safety index}

As shown in Fig. 5, the steel in concrete will be corroded if carbonation depth is larger than cover thickness. So the failure criterion can be given as 


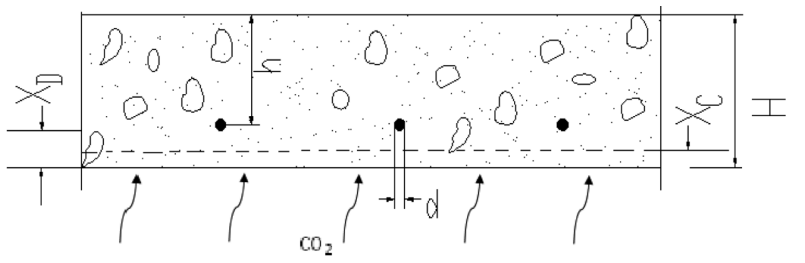

Fig. 5 Carbonation depth of reinforced concrete slab, where $X_{D}=$ cover thickness; $X_{C}=$ carbonation depth; $H=$ slab width; $h=$ effective depth; and $d=$ steel bar diameter.

$$
Z=\ln \left(\frac{X_{D}}{X_{C}}\right)
$$

where $X_{D}$ is the concrete cover thickness and $X_{C}$ is the carbonation depth. Here $X_{D}$ and $X_{C}$ are considered to obey the lognormal distribution, which are

$\ln \left(X_{D}\right): N\left(\mu_{D}, \sigma_{D}\right) ; \ln \left(X_{C}\right): N\left(\mu_{C}, \sigma_{C}\right)$

Because concrete cover is impossible to be below zero, so the failure state is $Z \leq 0$.

The safety index is calculated based on the FOSM method ${ }^{12}$ :

$$
\beta=\frac{\mu_{z}}{\sigma_{Z}}
$$

where $\mu_{Z}=\left.\ln \frac{X_{D}}{X_{C}}\right|_{\left(\mu_{D}, \mu_{C}\right)}=\ln \frac{\mu_{D}}{\mu_{C}} ; \sigma_{z}=\sqrt{V_{D}^{2}+V_{C}^{2}}$, here, $V_{D}, V_{C}$ are the coefficient of $X_{D}$ and $X_{C}$, and $V_{D}=\frac{\sigma_{D}}{\mu_{D}}, V_{C}=\frac{\sigma_{C}}{\mu_{C}}$.

By inserting these equations, Eq. (6) can be simplified as

$$
\ln \left(\frac{\mu_{D}}{\mu_{C}}\right)=\beta \sqrt{V_{D}^{2}+V_{C}^{2}}
$$

After calculation, the following can be obtained:

$$
\mu_{D}=\mu_{C} \cdot g_{\beta}
$$

and

$$
g_{\beta}=e^{\left(\beta \cdot \sqrt{V_{D}^{2}+V_{C}^{2}}\right)}
$$

It is shown that the nominal cover thicknesses are based on the grades of concrete and the environmental conditions of where the concrete is to be placed. Securing the correct cover thickness is very important for satisfying the target lifetime. All codes present the tolerance of cover thickness in order to consider the variation of installation quality. In this study, it is also assumed that the relationship between the nominal value and $\mu_{D}$ is expressed as the following 13

$$
X_{D}=f \cdot \mu_{D}(f=1.0 \sim 1.3)
$$

From (Eq. 4), the LCC model is formed as a function of the safety index through the concrete cover $X_{D}$ and the failure probability $P_{f}$, which is shown as

$$
\begin{aligned}
C_{r}= & (1+\lambda) \cdot C_{0}+(1+\lambda) \cdot W_{d} \cdot \operatorname{Costc} \cdot f \cdot \mu_{c} \cdot g_{\beta} \\
& +A \cdot W_{d} \cdot \operatorname{Costc} \cdot \Phi(-\beta)
\end{aligned}
$$

\subsection{Optimum design by minimum total costs}

The optimum design of a structure is conceptually a design scheme to study the economic aspects of structural design. The structural optimization problems are already formulated above as a function expressed by design variables. In this chapter, a reliability-based design to optimize the life cycle cost is studied and investigated. In order to obtain the optimal safety index and based on the basic concept of optimum design, it is expressed as

$$
\frac{\partial C_{T}}{\partial \beta}=0
$$

According to (Eq. 11), the following can be obtained, which is

$$
\begin{aligned}
\frac{\partial C_{T}}{\partial \beta}= & (1+\lambda) \cdot f \cdot W_{d} \cdot \operatorname{Costc} \cdot \mu_{C} \cdot \frac{\partial g_{\beta}}{\partial \beta} \\
& +A \cdot W_{d} \cdot \operatorname{Costc} \cdot \frac{\partial \Phi(-\beta)}{\partial \beta}=0
\end{aligned}
$$

From this equation it's clear that values of $W_{d}$ and Costc are not necessary. Then from (Eq. 9), the following is obtained

$$
\frac{\partial g_{\beta}}{\partial \beta}=\sqrt{V_{D}^{2}+V_{C}^{2}} \cdot e^{\beta \cdot \sqrt{V_{D}^{2}+V_{C}^{2}}}
$$

And based on the concept, it is well known that

$$
\frac{\partial \Phi(-\beta)}{\partial \beta}=-\phi(-\beta)
$$

So (Eq. 12) is simplified as

$$
f \cdot(1+\lambda) \cdot \mu_{C} \cdot \sqrt{V_{D}^{2}+V_{C}^{2}} \cdot e^{\beta \cdot \sqrt{V_{D}^{2}+V_{C}^{2}}}-A \cdot \phi(-\beta)=0
$$

This helps to get the result of the safety index, as in Fig. 6. To obtain an optimum solution, linear or nonlinear programming techniques are used. In the process of calculation, the dichotomy

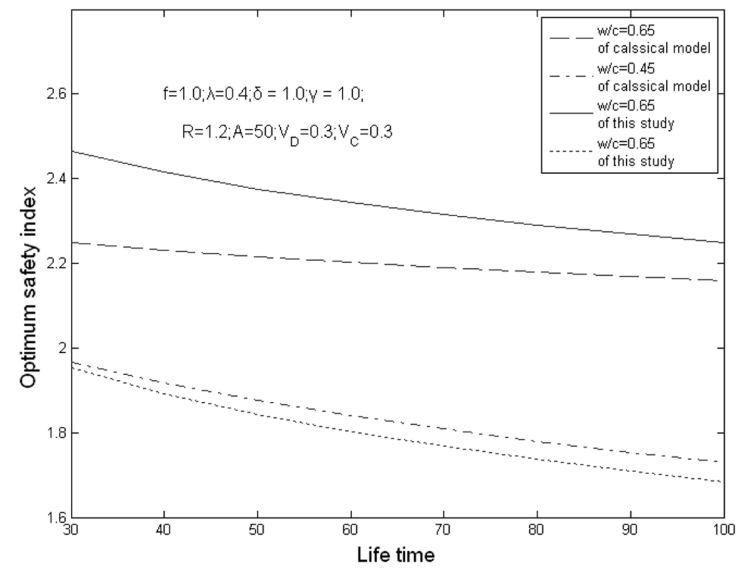

Fig. 6 Comparison of optimum safety indexes for life time with different water cement ratios. 
method is adopted.

Figure 6 shows the differences of the results between the classical polynomial simplification and the method used in this study under the same conditions. Obviously, the polynomial approximation brings a large error while the method used here is more accurate and more necessary to get a more convincing result.

It is defined that the dimensionless expected total cost is

$$
\operatorname{Cost}^{*}=f \cdot(1+\lambda) \cdot \mu_{C} \cdot e^{\beta \cdot \sqrt{V_{D}^{2}+V_{C}^{2}}}+A \cdot P_{f}
$$

Figure 7 describes that in each case, there is surely a certain $\beta$ which leads to a minimum total cost, and in the same case the cost will increase as the lifetime level goes higher and the failure cost factor gets larger. After the evaluation, the minimum expected total cost could be determined based on the optimum $\beta$ (Fig. 8). Then, the optimal concrete cover thickness is calculated on different conditions.

Figures 8 and 9 indicate that the low lifetime level and the small water-cement ratio bring a low total cost. Also, the smaller amount of uncertainties in the construction of concrete cover and in the

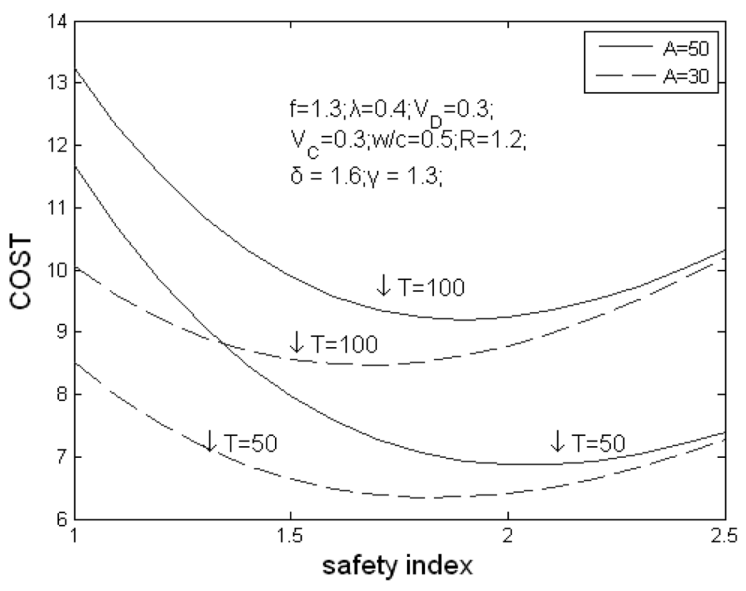

Fig. 7 Dimensionless expected total cost for safety index in different lifetime levels with both failure cost factors (under an easy to dry environment with good quality normal concrete and a water-cement ratio of 0.5 ).

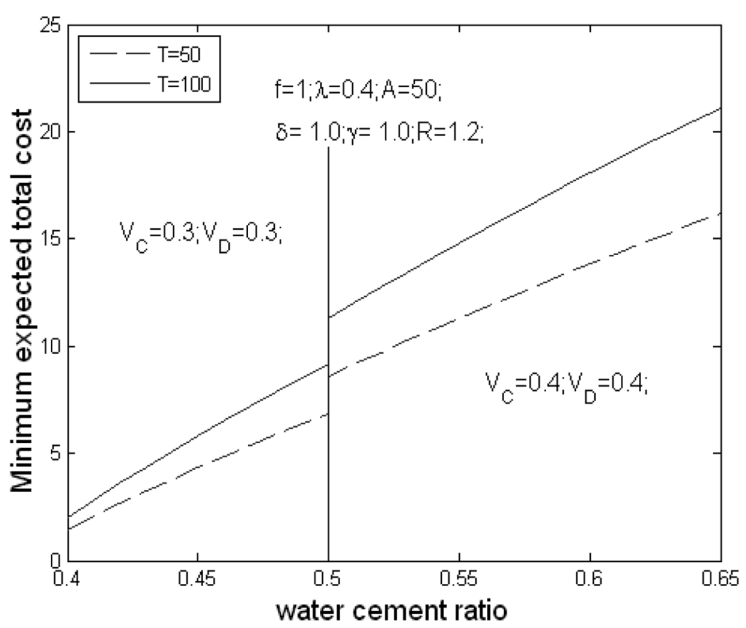

Fig. 8 Minimum expected total cost for w/c in different $V_{D} V_{C}$ and lifetime levels.

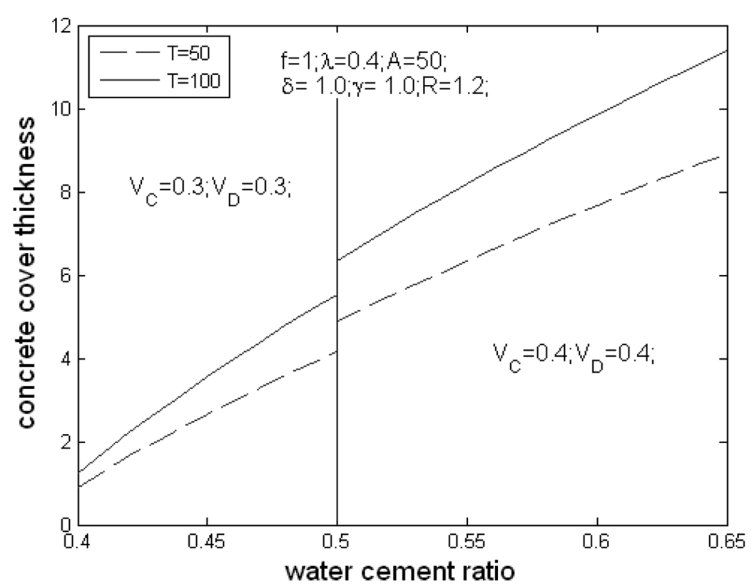

Fig. 9 Optimum concrete cover thickness for water cement ratio in different $V_{D} V_{C}$ and two lifetime levels.

carbonation depth will be better. How each parameter affects the total cost is tested in the following.

\section{Sensitivity analysis}

It can be seen from (Eq. 13) that the optimal reliability index $\beta$ mainly depends on

1) Variation of design parameters, e.g. coefficients of variation of $\mu_{D}, \mu_{C}, V_{D}$ and $V_{C}$

2) Relative cost factor of structural failure $C_{f}$ for initial cost, $A$

3) Maintenance cost factor, $\lambda$

4) Nominal factor of $X_{D}$ to $\mu_{D}, f$

5) The water to cement ratio, $w / c$

6) Lifetime, $T$

7) Direction coefficient considering environmental effects, $\delta$

8) Quality coefficient considering concrete quality, $\gamma$

It is evident that all these vary from case to case. And in the calculation process, these coefficients are only given as one case. Therefore, it is appropriate to work out some typical cases and carry out parametric studies for each case to determine the optimal reliability index. As shown in (Eq. 13), the effects of $V_{D}$ and $V_{C}$ are the same, so they are defined to be changed isochronously. It is also well-known that a smaller value of the coefficient of variables indicates a smaller amount of uncertainty or randomness in the variable. In many engineering problems, a value of $0.1 \sim 0.3$ is common for a random variable. ${ }^{12}$ In this paper, 0.3 is increased to 0.4 . The selection of any specific value for failure cost is somewhat arbitrary. Here, sensitivity analysis is carried out, in which the minimum expected total cost based on the optimum safety index is calculated in order to see the relationship between the two. The values for selection are shown in Table 2 .

Although many parameters are calculated, generally there are only three parts which affect the $\operatorname{cost} C_{T}$ : environment $(\delta, \gamma$ and $f)$, design $(V, w / c$ and $T)$ and maintenance $\operatorname{cost} C_{M}$, and failure cost $C_{f}$ $((\lambda$ and $A)$. We analyze this as shown in Figs. 10 to 12.

Fig. 10 describes that in the wet environment and with good quality concrete, where the expected total cost will have a relatively smaller value. It is easy to understand that these two will lead to a good quality concrete cover for less maintenance cost and a relatively smaller risk of failure with the same depth which means they have the same initial cost. Also the perfect construc- 
Table 2 Ranges of the parameters for sensitivity analysis.

\begin{tabular}{c|l|l}
\hline $\begin{array}{c}\text { Notations of } \\
\text { parameters }\end{array}$ & \multicolumn{2}{|c}{ Ranges of the parameters } \\
\hline \hline$V_{D}, V_{C}$ & A smaller amount of uncertainty in the variable: 0.1 & A larger amount of uncertainty in the variable: 0.4 \\
\hline $\mathrm{A}$ & The lower factor of $C_{f}$ for $C_{I}: 30$ & The higher factor of $C_{f}$ for $C_{I}: 50$ \\
\hline$\lambda$ & The lower factor of $C_{M}$ for $C_{I}: 0.1$ & The higher factor of $C_{M}$ for $C_{I}: 5$ \\
\hline$f$ & Nominal factor in perfect construction condition: 1.0 & Nominal factor of the limit value permitted: 1.3 \\
\hline$w / \mathrm{c}$ & Lower value used in the common structures: 0.4 & Higher value used in the common structures: 0.6 \\
\hline$T$ & The lower design lifetime of structures: 30 & The usual lifetime: 100 \\
\hline$\delta$ & environment difficult to dry, North direction $\rightarrow 1.0 ;$ & Environment easy to dry, south direction $\rightarrow 1.6$ \\
\hline$\gamma$ & general: 1.0 & Upper surface: 1.3 \\
\hline
\end{tabular}

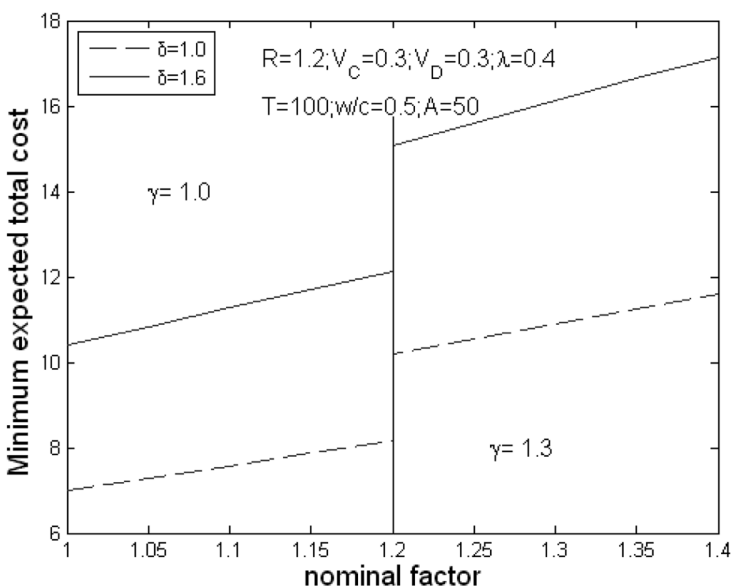

Fig. 10 Optimum safety index-based minimum expected total cost for $f, \delta$ and $\gamma$.

tion will reduce the cost according to the Figure and Fig. 11 shows that buildings with shorter lifetimes will cost less, and the less variability for the cover thickness and the smaller water cement ratios will also have better performance. Figure 12 illustrates the smaller maintenance factor that should be achieved and that the value of 50 for the failure factor is more proper to use.

\section{Application of the proposed design}

To verify the feasibility of the proposed LCC-based optimal

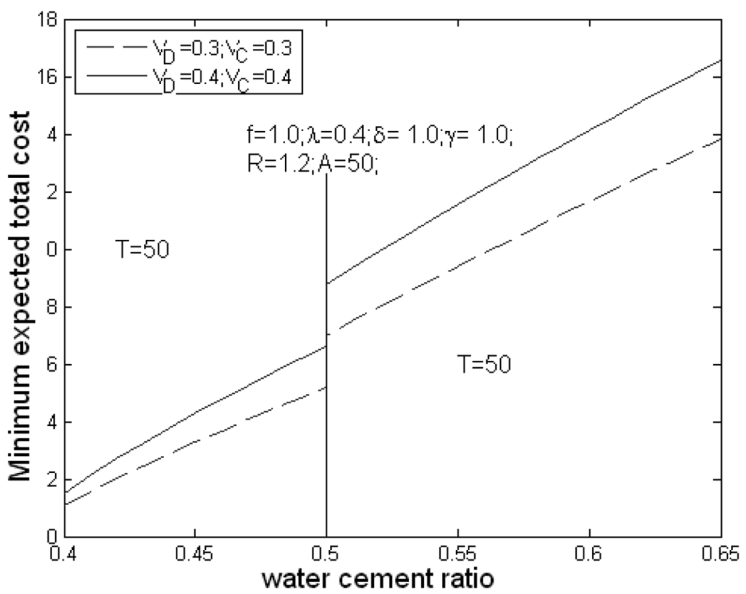

Fig. 11 Optimum safety index-based minimum expected total cost for w/c, $T$ and $V$. durability approach, an example of a civil structure exposed to carbonation is calculated in this study as follows

1) Assuring carbonation depth

The structure is supposed to be designed to have a lifetime of 100 years. According to the statics of the climate and atmosphere, the easy to dry and normal concrete with general concrete quality is considered, so the coefficients $R, \delta$ and $\gamma$ respectively are 1.2, 1.6 and 1.3. As a common structure, the ratio of water to cement used is 0.60 ; thus according to (Eq.1), the carbonation depth

$$
X_{C}=1.72 \cdot R \cdot(w / c-0.38) \cdot \sqrt{t} \cdot \delta \cdot \gamma=9.4449
$$

2) Form the LCC equation for safety index

From the analysis, the value of the factor of the structural failure cost for the initial cost is better to be 50; and by doing a survey in the certain place, the maintenance fee can be acquired, which is usually not high especially for civil structures. Hence, the parameter $\lambda=0.4$. According to (Eq. 4), the LCC equation is:

$$
C_{T}=1.4 \cdot C_{0}+1.4 \cdot W_{d} \cdot \operatorname{Costc} \cdot X_{D}+50 \cdot P_{f} \cdot W_{d} \cdot \operatorname{Costc}
$$

Based on the construction code, the nominal factor for cover thickness $f=1.2$, and the concrete cover is (Eq. 10):

$X_{D}=1.2 \mu_{D}$

And the total cost as a function of the safety index is as shown

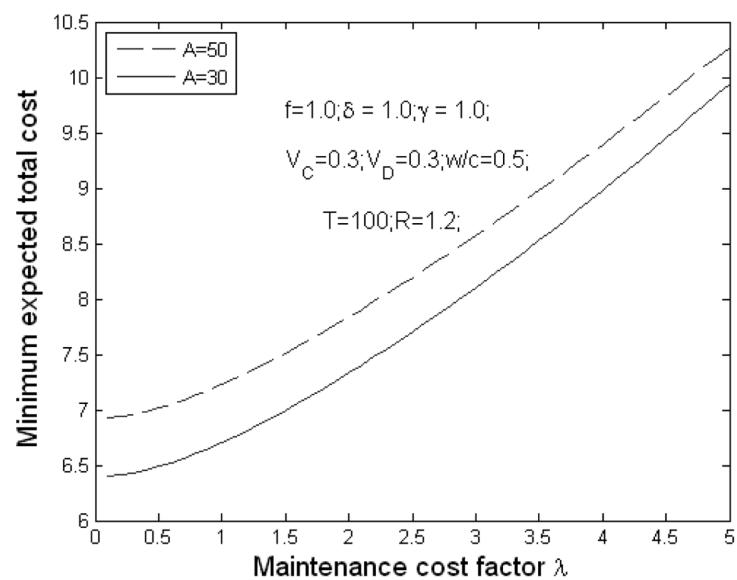

Fig. 12 Optimum safety index-based minimum expected total cost for $\lambda$ and $A$. 
in Eq. (11):

$$
\begin{aligned}
C_{T} & =1.4 \cdot C_{0}+1.4 \cdot W_{d} \cdot \operatorname{Costc} \cdot 1.2 \cdot 9.4449 \cdot g_{\beta}+50 \cdot W_{d} \cdot \operatorname{Costc} \cdot \Phi(-\beta) \\
& =1.4 \cdot C_{0}+15.8674 \cdot W_{d} \cdot \operatorname{Costc} \cdot g_{\beta}+50 \cdot W_{d} \cdot \operatorname{Costc} \cdot \Phi(-\beta)
\end{aligned}
$$

3) Obtain optimum cover thickness by minimum costs

A value of 0.3 for $V_{D}$ and $V_{C}$ is taken here. Optimizing the total cost it can be shown as

$$
\begin{aligned}
\frac{\partial C_{T}}{\partial \beta} & =15.8674 \cdot \sqrt{V_{D}^{2}+V_{C}^{2}} \cdot \exp \left(\beta \cdot \sqrt{V_{D}^{2}+V_{C}^{2}}\right)-50 \cdot\left(\frac{1}{\sqrt{2 \pi}} e^{-\frac{1}{2} \beta^{2}}\right) \\
& =6.7325 \cdot \exp (\beta \cdot 0.4243)-50 \cdot\left(\frac{1}{\sqrt{2 \pi}} e^{-\frac{1}{2} \beta^{2}}\right)=0
\end{aligned}
$$

Thus, the dimensionless expected total cost is

$$
\operatorname{Cost}^{*}=15.8674 \cdot \exp (\beta \cdot 0.4243)+50 \cdot \int_{-\infty}^{-\beta} \frac{1}{\sqrt{2 \pi}} e^{-\frac{1}{2} \beta^{2}}
$$

The optimum safety index is very clear in Fig. 13 and applying the dichotomy method, the result can be obtained as $\beta_{\text {opt }}=1.1$.

The expected total cost is (Eq. 14): Cost $^{*}=32$.

Finally the target concrete cover thickness is calculated ((Eq. 8) and (Eq. 9)): $X_{D} \approx 18$.

As the carbonation depth is 9.4449 , the concrete cover thickness has to be greater. If safety and serviceability are the only considerations, the minimum thickness can be 10 . However, the calculated final value is 18 , which is explained below.

Based on (Eq. 5) once the thickness is given, the corresponding safety index $\beta$ can be obtained. Then, after the calculation of the probability of failure, the expected total costs are determined from (Eq. 12). Here, values of 10 24 for the cover thickness are taken for example, and the expected total costs are shown in Table 3.

It is very clear the optimal value corresponding to the minimum expected total cost is nearly half of the value, which leads to a value of 18

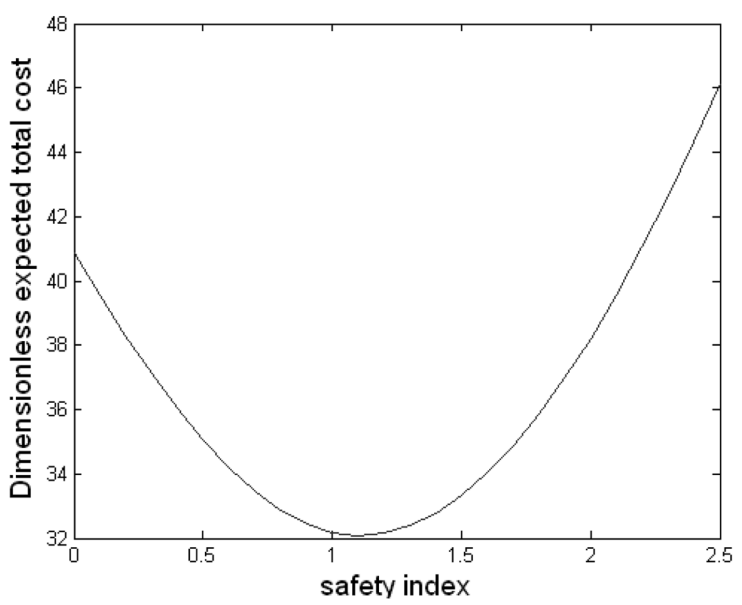

Fig. 13 The dimensionless expected total cost to vary against safety indexes for the example.
Table 3 Expected total cost of different cover thickness.

\begin{tabular}{c|c}
\hline Cover thickness & Expected total cost \\
\hline \hline 10 & 44.8 \\
\hline 11 & 41.8 \\
\hline 12 & 39.12 \\
\hline 13 & 36.86 \\
\hline 14 & 35.06 \\
\hline 15 & 33.72 \\
\hline 16 & 32.81 \\
\hline 17 & 32.28 \\
\hline 18 & 32.09 \\
\hline 19 & 32.18 \\
\hline 20 & 32.52 \\
\hline 21 & 33.05 \\
\hline 22 & 33.75 \\
\hline 23 & 34.58 \\
\hline 24 & 35.52 \\
\hline
\end{tabular}

\section{Conclusions}

In this study, the improved LCC-based optimal durability design of a concrete structure under carbonation was proposed. It has been shown that the methodology of this study was more rational and exact than the classical LCC-based optimal model which used the approximation of polynominal fitting. Through this study, the optimal reliability index can be calculated and the whole life cycle cost of the concrete structure is minimized. Therefore, the major effort in LCC-based durability design should be in the derivation of solutions to the optimal reliability index.

\section{Acknowledgments}

This work was supported by the Korea Research Foundation Grant funded by the Korean Government (KRF-2008-355D00020).

\section{References}

1. Frangopol, D. M., Lin, K. Y., and Estes, A. C., "Life-Cycle Cost Design of Deteriorating Structures," Journal of Structural Engineering, ASCE, Vol. 123, No. 10, 1997, pp. 1390 1401.

2. V., MacGregor, J. C. and Cornell, C. A., "Development on a Probability Based Load Criteria for American National Standard A58," NBS Special Publication No. 577, National Bureau of Standards, US Department of Commerce, Washington DC, 1980.

3. Japan Concrete Institute, Report of the committee for Concrete Carbonation, 1993.

4. Ying-Yu L. and Qui-dong W, "The Mechanism for Carbonation of Mortars and the Dependence of Carbonation on Pore Structure, Concrete Durability," SP-100, Vol. 2, American Concrete Institute, Detroit, 1987, pp. 1915 1943.

5. Melchers, R. E., "Structural Reliability Analysis and Prediction," John Wiley and Sons, Chichester, UK, 1999.

6. Yoon, I. S., Copurog 'lu, O., and Park, K. B., "Effect of Global Climatic Change on Carbonation Progress of Concrete," Atmospheric Environment, Vol. 41, No. 34, 2007, pp. 7274 7285. 
7. Clifton, J. R., "Predicting service life of concrete," $A C I$ Materials Journal, Vol. 90, No. 6, 1993, pp. 611 617.

8. Izquirerdo, D., "Basis of Design of Probabilistic Analysis of Reinforcement Corrosion in Concrete," Polytechnic University of Madrid, Doctoral Thesis, 2003.

9. Izquirerdo, D., "Economical Opimization of Appraising Concrete Deterioration Process," Life-Cycle Performance of Deteriorating Structures-Assessment, Design and Management, Edited by D.M. Frangopol et al., ASCE, 2003, pp. 37 48.

10. Ditlevsen, O. and Madsen, H. O., Structural Reliability
Methods, Wiley, 1996.

11. Li, Q., "A Method for Reliability-based Economic Design of Building Structures," Building Research \& Information, Vol. 28, No. 4, 2000, pp. 260 267

12. Handra, S. Mahadevan, Reliability Assessment Using Stochastic Finite Element Analysis, John Wiley \& Sons, Inc., 2000

13. Ken, K., Hironobu, T., and Isao, Y., "Reliability Based Optimal Thickness of Covering of Concrete Slab for Lifecycle (in Japanese)," in: Proc. JCOSSAR'91: The Second Conference on Structural Safety and Reliability, 1991, pp. 221 228. 